\title{
Podocalyxin EBP50 Ezrin Molecular Complex Enhances the Metastatic Potential of Renal Cell Carcinoma Through Recruiting Rac1 Guanine Nucleotide Exchange Factor ARHGEF7
}

\author{
Yung-Ho Hsu, ${ }^{*}$ Wei-Ling Lin, ${ }^{\dagger}$ Yi-Ting Hou, ${ }^{\dagger}$ \\ Yeong-Shiau $\mathrm{Pu},{ }^{\ddagger}$ Chia-Tung Shun, ${ }^{\S}$ \\ Chi-Ling Chen, ${ }^{\text {" }}$ Yih-Yiing Wu, ${ }^{\Perp}$ Jen-Yau Chen, ${ }^{\dagger}$ \\ Tso-Hsiao Chen, ${ }^{*}$ and Tzuu-Shuh Jou ${ }^{\text {tq }}$ \\ From the Department of Internal Medicine," Taipei Medical \\ University-Shuang Ho Medical Center, Taipei; the Departments of \\ Internal Medicine, ${ }^{\dagger}$ and Urology, ${ }^{\ddagger}$ National Taiwan University \\ Hospital and National Taiwan University College of Medicine, \\ Taipei; the Department of Pathology, National Taiwan University \\ Hospital, Taipei; the Department of Forensic Medicine, ${ }^{\S}$ National \\ Taiwan University College of Medicine, Taipei; the Graduate \\ Institute of Clinical Medicine, "National Taiwan University \\ College of Medicine, Taipei; and the Department of Pathology," \\ Cathay General Memorial Hospital, Taipei, Taiwan
}

Podocalyxin was initially identified in glomerular podocytes to critically maintain the structural and functional integrity of the glomerular ultrafiltrative apparatus. Lately, it has emerged as a malignant marker in tumors arising from a variety of tissue origins. By immunohistochemistry, we identified that $9.6 \%$ of renal cell carcinoma patients overexpress this protein. This subset of patients had significantly shorter disease-specific and overall survivals, and, importantly, we established podocalyxin overexpression as an independent prognostic factor for latent distant metastasis with multivariate analysis. Podocalyxin down-regulation by small interfering RNA led to defective migration in model renal tubular cells, which was corrected by re-expression of podocalyxin. The activity of the small GTPase Rac1, a wellcharacterized modulator of cell migration, was diminished by podocalyxin knock-down. Conversely, podocalyxin overexpression in human embryonic kidney cells up-regulated Rac1 activity, which depended on a complex formed by podocalyxin, ERMbinding phosphoprotein 50, ezrin, and ARHGEF7, a Rac1 activator. Therefore, podocalyxin can serve as a biomarker to identify renal cell carcinoma patients with higher metastatic potential for more aggressive intervention at earlier clinical stages. (Am J Pathol 2010, 176:3050-3061; DOI: 10.2353/ajpath.2010.090539)

Renal cell carcinoma (RCC) accounts for approximately $3 \%$ of adult malignancy and more than $85 \%$ of renal cancers. Although the prognosis of RCC is chiefly related to the clinical stage of disease, useful markers are valuable for both therapeutic decision-making and patient counseling.

Podocalyxin (PC) plays a critical role in maintaining the ultrastructure of glomerular podocytes. When PC genes are genetically deleted, mice die of anuric renal failure within 24 hours after birth. ${ }^{1}$ The foot processes of glomerular podocytes in these mice are effaced, and the filtration slits are obliterated. An aberrant cell-cell junctional complex is found between the fused foot processes in these mice, implying a loss of antiadhesive function from eliminating PC. Indeed, overexpressed PC confers an antiadhesion phenotype in Cos cells, and this antiadhesive function is presumably through the abundant sialic and sulfatic acid modification in the extracellular domain of PC, which thus exerts an electric repulsive force between neighboring cells. ${ }^{2}$

$\mathrm{PC}$ is a transmembrane sialomucin that is structurally related to the vascular endothelium marker CD34. PC is a downstream target gene of the WT1 tumor suppressor, ${ }^{3}$ and its expression is negatively regulated by $\mathrm{p} 53 .{ }^{4} \mathrm{Al}-$

Supported by National Science Council grants (NSC94-3114-P002-002Y[3], NSC95-2320-B002-048, and NSC97-3112-B-002-041) and National Taiwan University Hospital grants (NTUH-96S617 and NTUH-97A08-1) to T.-S.J.

\footnotetext{
Accepted for publication February 25, 2010.
}

Supplemental material for this article can be found on http://ajp. amjpathol.org.

Address reprint requests to Tzuu-Shuh Jou, M.D., Ph.D., Department of Internal Medicine, National Taiwan University Hospital and National Taiwan University College of Medicine, No. 7, Chung-Shan S. Road, Taipei, 100 Taiwan. E-mail: jouts@ntu.edu.tw. 
though initially identified as a resident protein in glomerular podocytes that governs the filtering function, an emerging role of PC has been identified in many organs other than renal tissues. ${ }^{5-8}$ Moreover, besides its physiological functions, PC has also been implicated in many disease processes including malignant progression. ${ }^{9,10}$ Aberrant PC expression has been reported in leukemic blastic cells, ${ }^{11,12}$ undifferentiated thyroid carcinomas, ${ }^{13}$ and endothelial cells surrounding hepatocellular carcinoma. ${ }^{14}$ Furthermore, previous studies have shown that PC overexpression is a predictor of breast cancer progression $^{9}$ and that PC-like gene variants are associated with risk of both prostate cancer and tumor aggressiveness. ${ }^{10}$

As RCC is originated from renal tubules and we had identified PC expression in canine renal tubules, ${ }^{7}$ we reasoned that PC may also be an important modulator of RCC tumorigenesis. In this study, we demonstrate that PC is overexpressed in a subset of RCC cases, and its aberrant expression pattern apparently contributes to higher distant metastasis frequency.

\section{Materials and Methods}

\section{Patient Selection and Tumor Samples}

Formalin-fixed paraffin-embedded samples were obtained from 303 patients with primary RCC who received radical or partial nephrectomy between January 1995 and December 2004 with institutional review board approval (National Taiwan University Hospital, Taipei, Taiwan). The clinical information and the outcome status of the patients were obtained through chart reviewing, questionnaire recording, telephone calling, and database referral in the national mortality recording system. The diagnosis, histological typing, and Fuhrman nuclear grading were confirmed by at least two pathologists. Staging was based on the pathological finding according to the American Joint Committee on Cancer TNM staging of renal cell carcinoma (2002).

\section{Immunohistochemistry Analysis of the RCC Specimen}

Avidin-biotinlyated peroxidase was purchased from DakoCytomation (Denmark), and standard IHC protocol was used. To provide a rigid control and enhance the specificity of the staining result, a pair of adjacent $5-\mu \mathrm{m}$ sections from every nephrectomy tissue was processed for immunohistochemistry $(\mathrm{IHC})$ in parallel. While one section was processed with a previously characterized affinity-purified rabbit anti-PC antibody, ${ }^{7,15}$ the other adjacent section from the same paraffin block was stained with the same antibody that had been pre-absorbed with the specific immunizing antigen. PC expression status was assessed after a pathologist, who was unaware of the pathological features or clinical outcomes of the cases under inspection, had examined the whole area of each slide. Positively PC-expressed RCC samples were those which had staining intensity approaching those in glomeruli and endothelia and whose PC staining intensity by the affinity purified antibody was clearly higher than that on the stained section by the pre-absorbed antibody.

The experimental procedure of generating and purifying PC-specific antibody and the experimental details for performing $\mathrm{IHC}$ have been previously described. ${ }^{7,15}$

\section{Computer-Aided Quantitative Analysis of PC Stain}

To verify the validity of this classical $\mathrm{IHC}$ analysis, we included all 29 PC-positive and the other 29 randomly selected PC-negative samples for the computer-aided quantitative analysis. Five areas from each IHC sample were randomly selected and examined under a microscope, and the images were converted to digital files using a CCD camera (Pursuit model, SPOT diagnostic) and the installed software program. PC staining intensity on each image file was assessed with computerized image analyzing software (Image-Pro Plus version 6.0, Media Cybernetics, Inc.). We used two color segmentations; one recognized PC-positive brown cells and the other PC-negative blue background cells. Integrated optical density was obtained as total number of brown pixels multiplied by the brown intensity of those pixels, and quantitative IHC staining value (QISV) was calculated as integrated optical density divided by total area occupied by the brown and blue cells.

\section{Assessment of Podocalyxin Expression from Paraffin-Embedded Tissue Blocks by Semiquantitative RT-PCR}

Five consecutive 10- $\mu$ m-thick sections from each paraffin-embedded tissue block were prepared. The tumor infiltrated region was identified by H\&E staining on one of the sections. Then, the identified tumor parts were collected into an Eppendorf tube from the other unstained tissue sections with a razor blade. The materials were mixed with $1 \mathrm{ml}$ of xylene and shaken for 10 minutes on a vortex to dissolve the paraffin. After clearing off the $x y$ lene, the samples were rehydrated in gradient ethanol. Then, the ethanol was evaporated by a spinning vacuum, and the samples were digested in $1 \mathrm{mg} / \mathrm{ml}$ proteinase $\mathrm{K}$ solution at $55^{\circ} \mathrm{C}$ for 4 hours. The RNA was extracted using TRIzol reagent (Invitrogen) before first strand cDNA was amplified using a High Fidelity PrimeScrip RT-PCR Kit (Takara Bio Inc.) according to the manufacturers' instructions. The human PC sequence was amplified with the following primer pair: 5'-TCCCTCCTTCTCGGCG-3' and 5'-GAAAGGTGGCTTTGACTGCTC-3', and the condition for PCR was as followed: $94^{\circ} \mathrm{C} 30$ seconds, $54^{\circ} \mathrm{C}$ 30 seconds, and $72^{\circ} \mathrm{C} 30$ seconds for 30 cycles. Human $\beta$-actin sequence was amplified with the following primer pair: 5'-AGCACTGTGTTGGCGTACAG-3' and 5'-GGACTTCGAGCAAGAGATGG-3' as an internal control $\left(94^{\circ} \mathrm{C}\right.$ 30 seconds, $56^{\circ} \mathrm{C} 30$ seconds, and $72^{\circ} \mathrm{C} 30$ seconds for 25 cycles). 


\section{Antibodies}

The mouse anti-Ezrin monoclonal and rabbit anti-EBP50 polyclonal antibody were from Lab Vision and Abcam, respectively. The anti-Myc and anti-HA epitope, and anti$\beta$-tubulin monoclonal antibodies were from Sigma. The mouse anti-Rac1 was from Upstate Biotechnology. The rabbit anti-ARHGEF7 antibody was from Cell Signaling Technology.

\section{Plasmids Construction}

DNA for full-length EBP50, the PDZ1 domain of EBP50 (residues 1-148), the PDZ2 domain of EBP50 (residues 149-297), the C-terminal one-third of ARHGEF7 (residues 401-646), and the PDZ motif-deleted ARHGEF7 (residues 401-641) were cloned into pGEX2T or pET32a for bacterial expression by standard molecular cloning procedure and verified by automatic DNA nucleotide sequencing. Plasmids expressing HA-tagged ezrin and Myc-tagged PC, FLAG-tagged EBP50 mammalian expression construct, and its related mutants were similarly derived from pcDNA3.1 (Invitrogen).

\section{Protein Purification and in Vitro Binding}

Bacterial-expressing glutathione-S-transferase (GST) fusion proteins and Thioredoxin-6His fusion proteins were expressed in DE3pLys strain and purified by glutathione beads and nickel-chelating resins, respectively according to standard protocols. All in vitro binding assays were incubated and washed in $10 \mathrm{mmol} / \mathrm{L}$ Tris, $150 \mathrm{mmol} / \mathrm{L}$ $\mathrm{NaCl}, 0.5 \% \mathrm{TX}-100$.

\section{Cell Culture and Transfection}

Madin Darby canine kidney (MDCK) type II and human embryonic kidney (HEK) 293 cells were cultured in Dulbecco's modified Eagles medium (DMEM) supplemented with $10 \%$ fetal calf serum at $37^{\circ} \mathrm{C}$ in a humidified incubator containing $5 \% \mathrm{CO}_{2}$. Transient transfection was performed using Lipofectamine 2000 (Invitrogen) according to the manufacturer's instruction. RNA interfering experiment for knocking down ARHGEF7 expression was conducted with small interfering RNA (siRNA) duplex targeting at human ARHGEF7 (Stealth, Oligo ID HSS113107) and a low GC matched negative universal control (Cat. No. 12935-200) ordered from the Invitrogen.

\section{Rac1 Activation Assay}

The p21-binding domain (PBD) of p21-activated kinase 1 (PAK1) was fused with glutathione-S-transferase to make a recombinant protein (GST-PBD). The procedure of preparing GST-PBD, processing cellular lysates to perform the pull down assay, and using anti-Rac1 antibody for Western blotting analysis was essentially as described before. ${ }^{16}$ The result was expressed as the signaling intensity of activated Rac1 recovered after GST-PBD pull down normalized by total Rac1 signal found in one-twentieth of the clarified cell lysate.

\section{Cell Aggregation Assay}

The assay was performed with modification of a wellestablished method. ${ }^{2,17}$ MDCK cells were cultured on $100-\mathrm{mm}$ dishes overnight in MEM containing $0.1 \mathrm{mmol} / \mathrm{L}$ $\mathrm{Ca}^{2+}$ supplemented with $5 \%$ dialyzed FCS. Subconfluent cell layers were rinsed twice with $\mathrm{Ca}^{2+}$ - and $\mathrm{Mg}^{2+}$-free PBS and detached by incubation in HBSS containing 1 $\mathrm{mmol} / \mathrm{L}$ EDTA at $37^{\circ} \mathrm{C}$ for 20 minutes. After washing twice in HBSS containing $1 \%$ BSA (HBSS/BSA), cells were resuspended $\left(5 \times 10^{5}\right.$ cells per $\left.\mathrm{ml}\right)$ in HBSS/BSA by three passages through an 18-gauge needle. The cell suspension (0.5 ml per well) was seeded in a 24-well ultralow attachment plate (Costar, USA) to inhibit cell adhesion to the substratum and allowed to aggregate for 0 to 120 minutes in the presence of $1 \mathrm{mmol} / \mathrm{L} \mathrm{CaCl} \mathrm{Ca}_{2}$ at $37^{\circ} \mathrm{C}$ on a rotating shaker $(80 \mathrm{rpm})$. The reaction was stopped by adding $0.5 \mathrm{ml}$ of $3.7 \%$ paraformaldehyde (Sigma) per well. We quantified aggregation by counting representative aliquots from each sample on a hematocytometer. The number of cellular aggregates of more than three cells and the total number of cells were counted from four 1-mm squares of the hematocytometer grid. At least 600 cells were counted from each sample. The percentage of aggregation was quantified as: $\left(\mathrm{N}_{0}-\right.$ $\left.N_{t}\right) / N_{O} \times 100$, where $N_{t}$ is the total number of aggregates at the incubation time $t$, and $N_{0}$ is the total number of cells. Each clone was seeded as a triplicate sample, and the result was shown in mean $\pm \mathrm{SE}$.

\section{Transwell Migration Assays}

To assess cell migration, $2 \times 10^{4}$ MDCK cells in $200 \mu$ l DMEM supplemented with $1 \%$ FBS were placed in the top chamber of transwell migration chambers $(8-\mu \mathrm{m}$ inserts, Costar). The lower chamber was filled with $500 \mu$ l DMEM supplemented with 10\% FBS plus recombinant human Hepatocyte Growth Factor (50 ng/ml; R\&D Systems). To simulate migration through matrix containing collagen, $100 \mathrm{mg} / \mathrm{ml}$ type I collagen was applied to the underside of the filter. After 15 hours, cells left over the upper surface of the transwell were removed from the membrane with a cotton swab, and cells having migrated onto the lower membrane surface were fixed and stained with Hoechst 33342. The filters were removed from the plastic holder, mounted onto glass slide, observed with a $\times 5$ objective, and photographed and recorded with a CCD camera (Pursuit model, SPOT diagnostic) to facilitate counting of the cells that migrated.

\section{Wound Healing Assay}

MDCK cells were seeded in 6-well plates with DMEM containing $1 \%$ FBS. Four to six hours after plating, the cells reached confluency and the MDCK monolayers were wounded by scraping using the tip of a 200- $\mu$ l pipette. The floating cells were removed with suction, and 
the culture was replenished with DMEM contained 10\% FCS. The process of wound healing was monitored by light microscopy and photographed at five randomly selected regions along the wound.

\section{Statistical Analysis}

Data for age, sex, tumor size, stage, grade, histological type, and PC status were obtained as baseline variables. Metastasis-free survival was measured from the date of surgery to the date of first clinical evidence of metastasis, date of death, or date of last follow-up, whichever came first. Disease-specific or overall survival was measured from the date of nephrectomy to the date of death attributable to RCC or all causes. The baseline characteristics of all 303 patients were compared between PC-positives and PC-negatives with Wilcoxon rank sum test for continuous variables and the Fisher exact test for categorical variables. To address the effect of PC expression pattern on the risk of metastasis after surgery in RCC victims, we excluded stage IV patients, and only patients presented with localized disease (stage I to III, $n=265$ ) were included for survival analysis. Metastasis-free, diseasespecific, and overall survivals of patients were estimated by the Kaplan-Meier method, and the difference in survival curves was tested by log-rank test. The hazard ratios and 95\% confidence intervals were estimated using the Cox proportional hazards regression model to assess the role of PC as an independent predictor of metastasis of RCC when put simultaneously with other baseline covariates. All $P$ values are two-sided, with a type I error of 0.05. Statistical analyses were performed with STATA 8.2 (College Station, Texas).

\section{Results}

\section{Podocalyxin Is Overexpressed in a Subset of RCC Patients Who Manifest an Increased \\ Latent Metastasic Potential and Poor Outcome}

Three hundred three RCC patients were included in this study; their relevant clinicopathological characteristics are provided in Supplemental Table S1 (http://ajp.amjpathol. org). Vascular endothelial cells displayed a strong PC expression pattern, which significantly confounded our attempt to evaluate the contribution of cancer cells on the $\mathrm{PC}$ expression in the samples by quantitative RT-PCR (see Supplemental Figure S1 at $h$ ttp://ajp.amjpathol.org). To definitively determine the PC expression pattern in human RCC specimens, we performed IHC in archived RCC paraffin block sections and analyzed PC expression by pathological examination. While we did not detect significant expression in renal tubular cells (Figure 1, A and B), PC overexpression was well noted in certain RCC specimens (Figure 1, C-F).

Twenty-nine patients $(9.6 \%)$ were assessed to overexpress PC in their cancerous cells. To confirm the result of our assessment for the PC expression level using traditional pathological evaluation, we used computerized
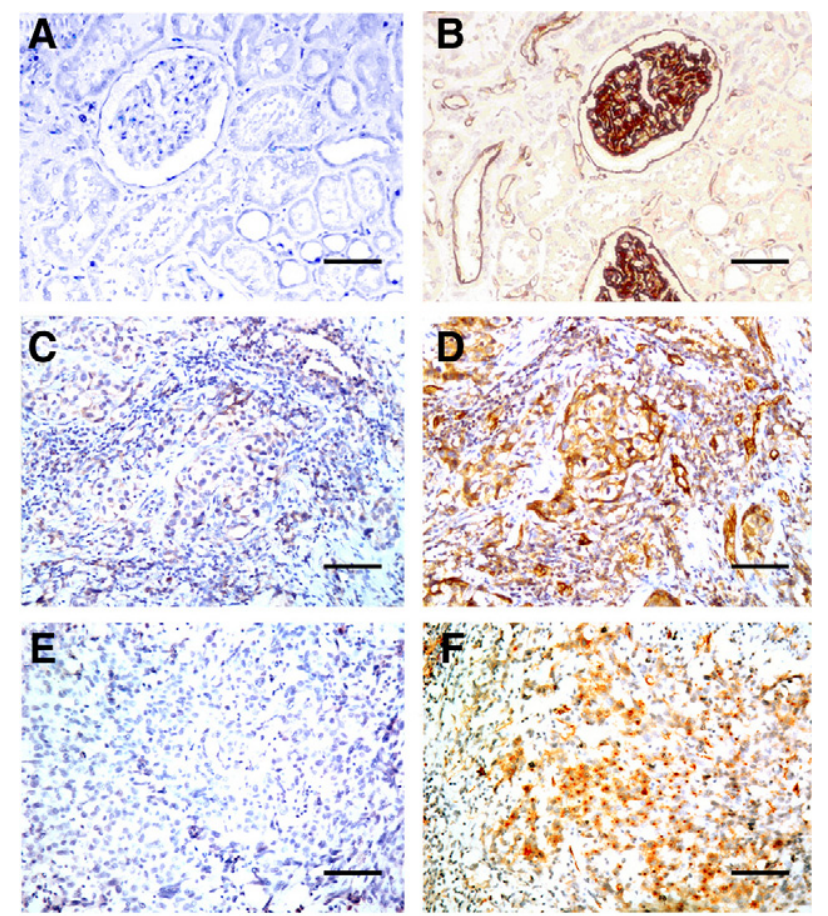

\section{G QISV}

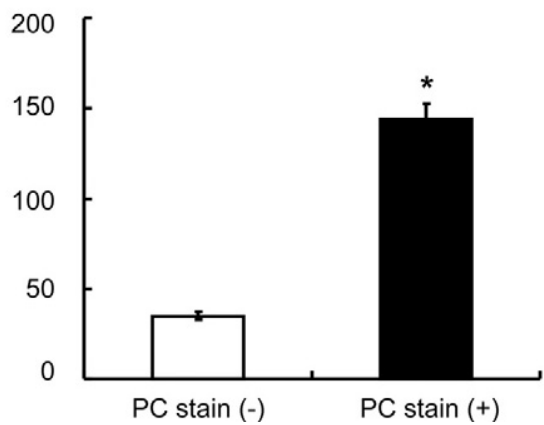

Figure 1. $P C$ expression in normal and cancerous renal sections. A: The renal paraffin section of a RCC patient was stained with the antigen-reabsorbed negative control antibody. A representative part of the disease-free section shows clean background in the normal glomerular, tubular, and vascular structures. B: An adjacent paraffin section of the slide shown in $\mathbf{A}$ was processed for IHC in parallel using the affinity purified anti-PC antibody, which displayed intensive staining in the glomerulus and vascular endothelial cells. Adjacent paraffin sections of a collecting duct $(\mathbf{C}, \mathbf{D})$ and a sarcomatoid (E, F) type RCC sample were processed for IHC using the negative control $(\mathbf{C}, \mathbf{E})$ and affinity purified $(\mathbf{D}, \mathbf{F})$ antibodies, respectively. Although the negative control antibody revealed faint background, the affinity-purified anti-PC antibody displayed intense membranous and cytosolic staining in the cancerous cells $(\mathbf{D}, \mathbf{F})$. In the sarcomatoid RCC sample stained by affinity purified anti-PC antibody, a prominent cytosolic aggregate was also noted. (A and $\mathbf{B}$, Scale bar $=30 \mu \mathrm{m}, \mathbf{C}-\mathbf{F}$, Scale bar $=15 \mu \mathrm{m}) \mathbf{G}$ : Computer-assisted quantitative staining analysis was used in all 29 PC stain (+) RCC samples, and another 29 randomly selected samples, which did not over-express PC (PC stain $[-]) .{ }^{*} P<0.0001$ versus PC stain $(-)$. The definition of quantitative IHC staining value (QISV) is explained in Materials and Methods section.

quantitative analysis on all 29 PC-overexpressing samples and another 29 randomly selected samples, which were assessed to be negatively stained with anti-PC antibody, for comparison. This quantitative analysis subjectively demonstrates an average of 144.01 arbitrary intensity units for the PC overexpressing samples in comparison with 34.82 units for the control group $(P<0.0001$; Figure $1 G)$. In conclusion, our results regarding the correlation between the clinical outcome and PC overexpression 
Table 1. Clinicopathological Manifestations of Podocalyxin (PC)-Positive and -Negative Renal-Cell Carcinoma

\begin{tabular}{|c|c|c|c|}
\hline Characteristic & $\begin{array}{c}\text { PC-positive } \\
\text { tumors } \\
(n=29)\end{array}$ & $\begin{array}{c}\text { PC-negative } \\
\text { tumors } \\
(n=274)\end{array}$ & $\begin{array}{c}\text { Significance } \\
(P)\end{array}$ \\
\hline \multicolumn{4}{|l|}{ Age } \\
\hline Mean (SD) & $57.4(12.9)$ & $61.0(14.1)$ & 0.15 \\
\hline \multicolumn{4}{|c|}{ (12.4) } \\
\hline $\mathrm{F}$ & $8(28 \%)$ & $92(34 \%)$ & 0.678 \\
\hline M & $21(72 \%)$ & $182(66 \%)$ & \\
\hline \multicolumn{4}{|l|}{ Histological types } \\
\hline Clear-cell type & 17 (59\%) & 227 (83\%) & 0.003 \\
\hline Papillary & $3(10 \%)$ & $16(6 \%)$ & \\
\hline Chromophobe & $3(10 \%)$ & $19(7 \%)$ & \\
\hline Others & $6(21 \%)$ & $12(4 \%)$ & \\
\hline \multicolumn{4}{|l|}{ Tumor size } \\
\hline Mean (SD) & $7.1(4.1)$ & $6.1(3.2)$ & 0.281 \\
\hline \multicolumn{4}{|l|}{ Tumor grade } \\
\hline 1 & $1(4 \%)$ & $46(17 \%)$ & $<0.001$ \\
\hline 2 & $3(10 \%)$ & $159(58 \%)$ & \\
\hline 3 & $21(72 \%)$ & $59(21 \%)$ & \\
\hline 4 & $4(14 \%)$ & $10(4 \%)$ & \\
\hline \multicolumn{4}{|l|}{ Tumor stage } \\
\hline I & $10(35 \%)$ & 153 (56\%) & 0.003 \\
\hline II & $1(3 \%)$ & $41(15 \%)$ & \\
\hline III & $12(41 \%)$ & $48(17 \%)$ & \\
\hline IV & $6(21 \%)$ & $32(12 \%)$ & \\
\hline \multicolumn{4}{|l|}{$\begin{array}{l}\text { Lymph node } \\
\text { metastasis }\end{array}$} \\
\hline Present & $1(3 \%)$ & $14(5 \%)$ & 1.000 \\
\hline Absent & 28 (97\%) & 260 (95\%) & \\
\hline \multicolumn{4}{|l|}{ Distant metastasis } \\
\hline Present & $18(62 \%)$ & $51(19 \%)$ & $<0.001$ \\
\hline Absent & $11(38 \%)$ & $223(81 \%)$ & \\
\hline
\end{tabular}

(Tables 1 and 2, and Figure 2, A-C) were based on the classical pathologist's comprehensive survey on the whole area of each slide, and the computer-aided analysis on five random regions of selected specimen serves to demonstrate the validity of the traditional pathological examination.

The impact of PC overexpression on the clinical and pathological parameters of the RCC patients was shown in Table 1. Among the standard pathological predictors of clinical outcome, $\mathrm{PC}$ overexpression was strongly associated with the nuclear grading $(P<0.001) ; 25$ of 94 high-grade (grade 3 and 4) samples overexpressed PC, whereas only 4 of 209 low-grade (grade 1 and 2) samples overexpressed PC. Although the extent of PC expression was not associated with the primary tumor size $(P=$ $0.281)$, RCCs at advanced stages tended to overexpress PC $(P=0.003)$. Most significantly, $P C$ overexpression was associated with an increased frequency of distant metastasis. Eighteen of the 29 PC overexpressing patients (62\%) developed distant metastasis, whereas 51 of the 274 PC-negative patients (18\%) were found to have metastasis at initial presentation or during the follow-up period of their diseases.

Overexpression of PC in primary renal-cell tumors correlated with increased latent metastasis potential and compromised metastasis-free, disease-specific, and overall survivals (Figure 2). In univariate analysis (see Supplemental Table S2 at $h$ ttp://ajp.amjpathol.org.), the hazard ratio of PC overexpression was $8.38(95 \% \mathrm{Cl}=4.14-16.97, P<0.001)$ for metastasis-free survival and $8.85(95 \% \mathrm{Cl}=4.24-18.48$, $P<0.001)$ for disease-specific survival. To investigate whether PC overexpression in primary renal-cell carcinoma is an independent risk factor for tumor metastasis and clinical outcome, we performed multivariate analysis incorporating $\mathrm{PC}$ status, age, sex, tumor size, stage, grade, and histological type in the model as potential risk factors. The results established that PC overexpression is an independent and strong predictor of patients' tumor metastasis and clinical outcome; hazard ratios were $3.59(95 \% \mathrm{Cl}=1.51-$ $8.53, P=0.004)$ for metastasis-free survival and $7.46(95 \%$ $\mathrm{Cl}=2.51-22.22, P<0.001)$ for disease-specific survival (Table 2).

\section{PC Expression Confers Anti-Adhesive Nature on Canine Renal Tubular Cells}

The apparent molecular weight of PC on SDS-PAGE is 135-170 kDa, which differs considerably from the estimated molecular weight of $P C$ at $60 \mathrm{kD}$. This discrepancy is ascribed to extensive posttranslational modifications of PC by $\mathrm{N}$ - and O-linked glycosylation and further addition of sulfatic and sialic acid onto the O-glycan. Indeed, PC is the

Table 2. Multivariate Cox Regression Analysis for Metastasis-Free and Disease-Specific Survival

\begin{tabular}{|c|c|c|c|c|}
\hline \multirow[b]{2}{*}{ Variable } & \multicolumn{2}{|c|}{ Metastasis-free survival } & \multicolumn{2}{|c|}{ Disease-specific survival } \\
\hline & Hazard ratio $(95 \% \mathrm{Cl})$ & $P$ & Hazard ratio $(95 \% \mathrm{Cl})$ & $P$ \\
\hline PC expression (positive versus negative) & $3.59(1.51-8.53)$ & 0.004 & $7.46(2.51-22.22)$ & $<0.001$ \\
\hline Age & $1.03(0.99-1.06)$ & 0.085 & $1.03(1.00-1.08)$ & 0.039 \\
\hline Sex (female versus male) & $0.97(0.42-2.26)$ & 0.948 & $0.85(0.34-2.12)$ & 0.727 \\
\hline Tumor size & 1.07 (0.93-1.23) & 0.323 & $1.11(0.95-1.28)$ & 0.180 \\
\hline \multicolumn{5}{|l|}{ Tumor stage } \\
\hline II versus I & $2.27(0.49-10.5)$ & 0.293 & $3.29(0.63-17.17)$ & 0.157 \\
\hline III versus I & $6.75(2.4-18.65)$ & $<0.001$ & $10.20(2.93-35.42)$ & $<0.001$ \\
\hline \multicolumn{5}{|l|}{ Tumor grade } \\
\hline 2 versus 1 & $1.02(0.21-4.86)$ & 0.983 & $0.83(0.17-4.03)$ & 0.822 \\
\hline 3 versus 1 & $2.78(0.59-13.11)$ & 0.197 & $1.40(0.26-7.46)$ & 0.691 \\
\hline 4 versus 1 & $9.43(1.54-57.5)$ & 0.015 & $11.99(2.10-68.30)$ & 0.005 \\
\hline \multicolumn{5}{|l|}{ Histological type } \\
\hline Papillary versus clear & $0.65(0.15-2.8)$ & 0.568 & $0.22(0.04-1.33)$ & 0.099 \\
\hline Chromophobe versus clear & $0.55(0.15-2.01)$ & 0.365 & $0.23(0.04-1.44)$ & 0.117 \\
\hline Others versus clear & $0.84(0.24-2.95)$ & 0.779 & $1.71(0.52-5.60)$ & 0.375 \\
\hline
\end{tabular}




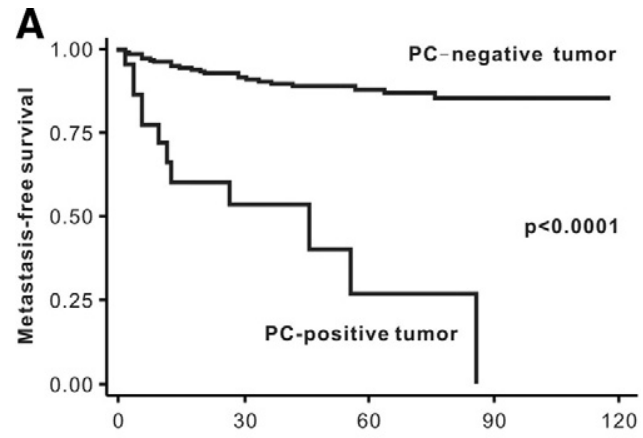

\section{B}

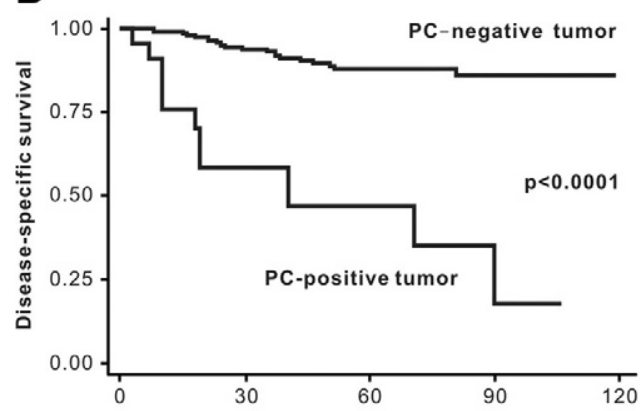

C

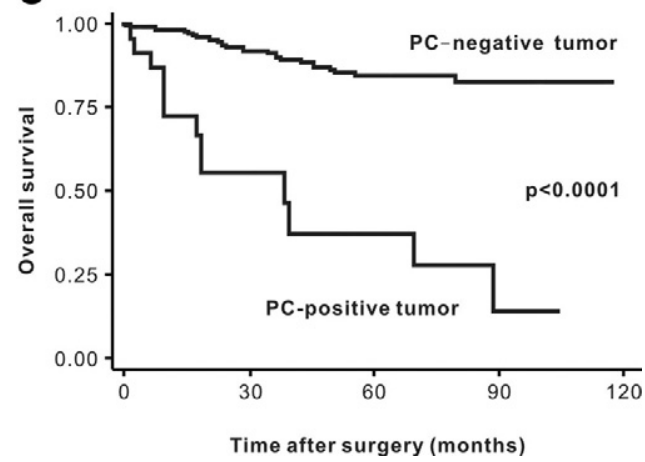

Figure 2. Kaplan-Meier survival analysis in patients with stages I to III renal cell carcinoma according to podocalyxin (PC) expression status. A: Metastasis-free survival. B: Disease-specific survival. C: Overall survival.

most sialated and sulfated protein in nephrons and is thought to play a critical role in maintaining the glomerular charge barrier function by adopting a negative charge. Furthermore, the electro-repulsive nature of PC is postulated to disrupt epithelial cell junctions between differentiating podocytes during normal kidney development to create the interdigital slit. PC knock-out mice die of anuria in early infancy and the interdigital slits of the PC-deficient mice are obliterated. ${ }^{1}$ In line with this hypothesis, overexpression of PC disrupts cell junctions in cultured canine MDCK cells and perturbs the polarized phenotype of human breast cancer cell line.2,9 To explore the influence of PC knockdown on the adhesive characteristic of cells, we used a series of previously characterized MDCK stable clones ${ }^{15}$; two of them expressed a siRNA that knocked down $80 \%$ of the endogenous PC protein ( $\mathrm{Si} 1$ and $\mathrm{Si} 2$ in Figure 3A), whereas the other two were derivatives from this knockdown mutant in which a full-length, but siRNA-resistant Myctagged PC construct was stably transfected to restore the expression of wild-type protein (R1 and R2 in Figure 3A).
A
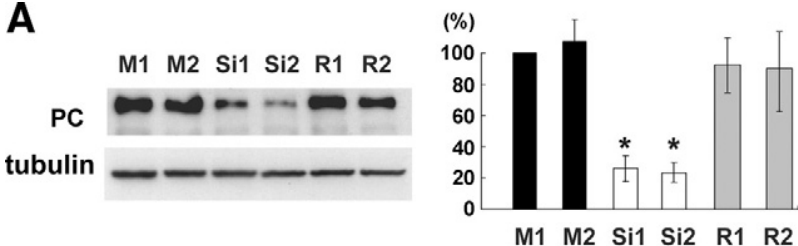

B

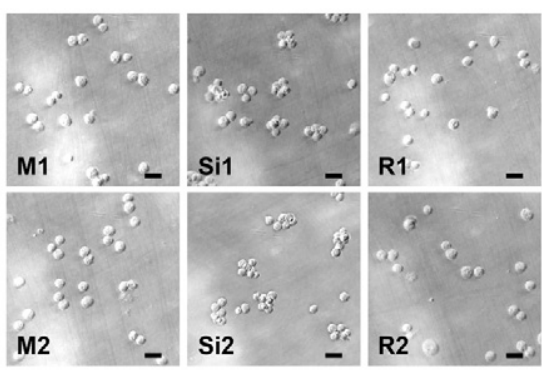

C

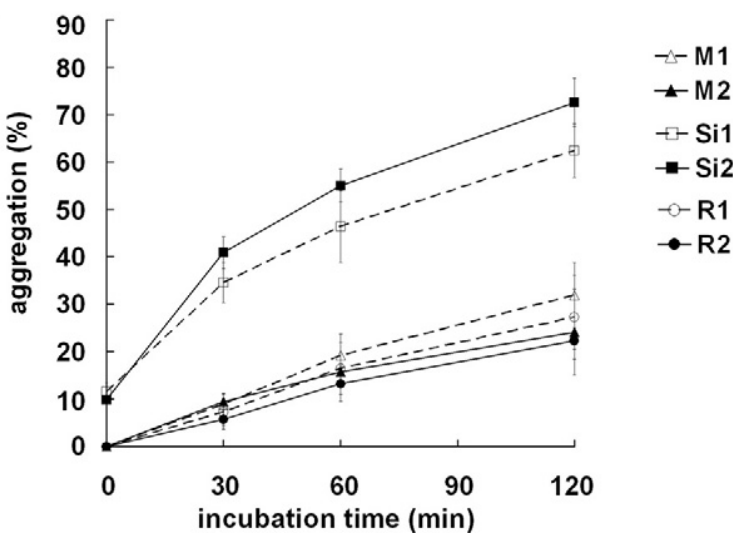

Figure 3. Antiadhesive effect of PC on cell aggregation. A, Left: Western blotting analysis of PC expression levels in mock-transfected MDCK clones (M1, M2), PC knock-down clones expressing siRNA targeted against endogenous PC (Si1, Si2), and the revertant MDCK clones expressing siRNA resistant Myc-tagged full length PC (R1, R2). The result showed a significant down-regulation of $\mathrm{PC}$, after normalization by the tubulin loading control, in the siRNA expressing clones. The quantitative result is shown in right panel $\left({ }^{*} P<0.05\right.$ verse $\mathrm{M} 1$ clone, triplicated experiments). B: Morphology of M, Si, and R MDCK clones after trituration in the presence of trypsin. Ten thousand cells were trypsinized in $0.0625 \%$ trypsin for ten minutes and then triturated with constant force using a p-1000 pipetman tip for fifteen times before the morphologies of the clones were detected and recorded by a CCD camera Magnification bar, $20 \mu \mathrm{m}$. C: Aggregation assay of M, Si, and R clones was performed as described in Materials and Methods section for the indicated time $(\mathrm{min})$. Bars: mean $\pm \mathrm{SE}$. The result was representative of three independent experiments.

These cells displayed quite contrasting phenotypes when we manipulated them in tissue culture procedures. The siRNA-expressing clones aggregated and appeared as small cellular clumps, whereas the $\mathrm{R}$ clones remained wellseparated right after trituration in trypsin solution similar to the mock control (Figure 3B). To better quantify the adhesive phenotype of these cell lines, we adopted a well-established cell aggregation assay, which quantitatively measures the strength of cell adhesion. 2,17 The PC knock-down clone aggregated in a percentage three times higher than the mock control (Figure 3C). By contrast, the R clone was dispersed to similar degree as the mock control, implying the increased aggregation observed in the knock-down cells was directly related to a defective PC function (Figure 3C). The difference in adhesive behavior between the mock-treated and PC defective cells appeared to depend 
A
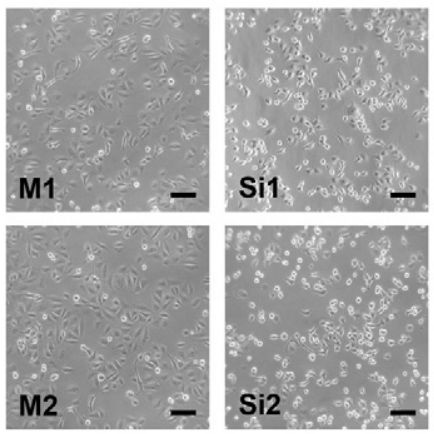
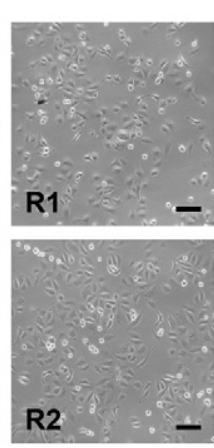

B

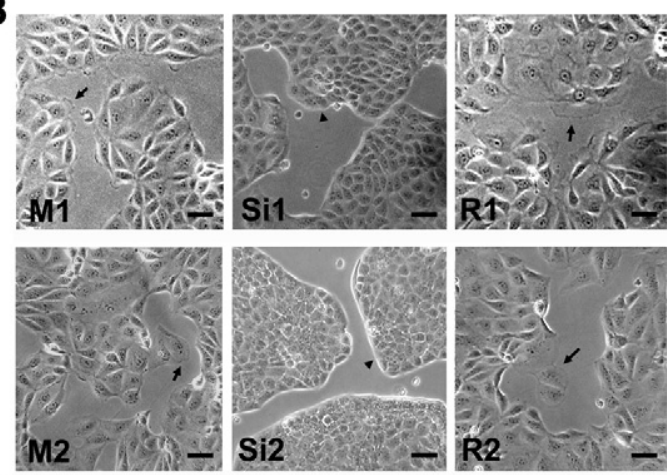

D

C

$\begin{array}{ccccccc}\text { Doxycycline } & 20 & 200 & 50 & 20 & 5 & 0 \\ \text { per } \mathrm{ml} & \mathrm{ng} & \mathrm{pg} & \mathrm{pg} & \mathrm{pg} & \mathrm{pg} & \mathrm{pg}\end{array}$

total Rac1

Rac1-GTP
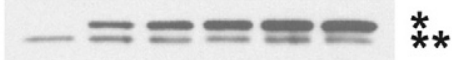

Doxycycline

per $\mathrm{ml}$

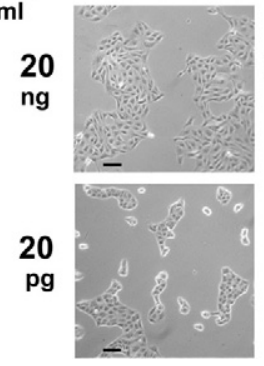

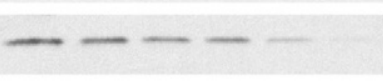

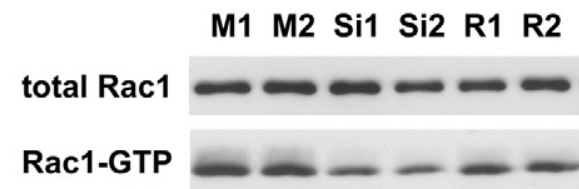

(\%)

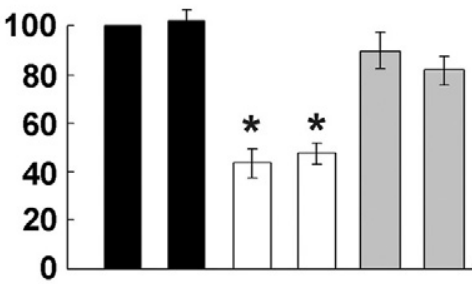

Figure 4. Podocalyxin (PC) knock-down leads to reduced cell spreading, lamellipodia formation, and Rac1 GTPase activity. A: M, Si, and R MDCK clones were trypsinized, and plated onto collagen I coated petri dish. The areas of cell spreading were quantified and photographed at 2 hours after plating. B: Nearly confluent monolayers of M, Si, and R cells were photographed right before the onset of contact inhibition. Arrows indicate lamellipodia structures; arrowhead, the smooth margin of Si cells where lamellipodia could barely be visible. C: Tetracycline-regulated Myc-tagged dominant-negative Rac1 expressing MDCK cells were cultured in the indicated concentrations of doxycycline for 24 hours and processed for Rac1 activation assay (upper) and phase contrast microscopic examination (lower). Western blotting analysis of total cellular lysates using Rac1 antibody detected both the ectopically expressed Myc-tagged Rac1N17 (*) and the endogenous Rac1 $\left({ }^{* *}\right)$. D: Rac1 activation assay were performed with M, Si, and R cells. The data shown here was a representative result from 3 independent experiments. The data shown were means $\pm \mathrm{SE}$ of each triplicate assay. ${ }^{*} P<0.05$ versus M1 clone. Magnification bars, $20 \mu \mathrm{m}$.

on factors operating independently of the E-cadherin function because neither the expression level nor subcellular localization of E-cadherin was affected by the knock-down or re-expression of PC (see Supplemental Figure S2 at http://ajp.amjpathol.org).

This result of knocking down the endogenous PC not only corroborates the antiadhesive effect of the PC molecule previously established using a PC overexpressing approach, ${ }^{2}$ but also confirms that the adhesive behaviors of the $\mathrm{Si}$ and $\mathrm{R}$ clones conform to the prediction and substantiates the eligibility of using these cell clones for studying the functions of PC.

\section{PC Expression Regulates Cell Morphology and Modulates Rac1 Small GTPase Activity}

The PC knock-down MDCK cells tended to spread less well compared with the mock control, and this defect could be reverted when the gene function was restored by expressing the rescue construct (Figure 4A). The mean area of extension per cell two hours after plating was $263 \pm 25 \mu \mathrm{m}^{2}$ for $\mathrm{M} 1,271 \pm 28 \mu \mathrm{m}^{2}$ for $\mathrm{M} 2,125 \pm$ $10 \mu \mathrm{m}^{2}$ for Si1, $132 \pm 11 \mu \mathrm{m}^{2}$ for Si2, $252 \pm 34 \mu \mathrm{m}^{2}$ for $\mathrm{R} 1,249 \pm 39 \mu \mathrm{m}^{2}$ for $\mathrm{R} 2$, respectively. Although the margins of the mock- and rescue construct-transfected clones were abundant with prominent lamellipodia, the PC knock-down cells lacked these structures (Figure 4B). Because lamellipodia are well known to be modulated by the small GTPase Rac1 and the characteristic poorly spread out morphology of the PC knock-down clone is reminiscent of a previously MDCK cell line when the endogenous Rac1 activity was inhibited by dominant negative Rac1 expression, ${ }^{18}$ we hypothesized that the Rac1 activity was regulated by the expression of PC and down-regulation of PC expression lead to decreased Rac1 activity. When dominant-negative Rac1 expression was induced using a tetracycline repressible system in MDCK cells, cells appeared smaller and less spread out in parallel with diminished Rac1 activity (Figure 4C). Indeed, Rac1 GTPase activity was compromised by $50 \%$ in PC knock-down MDCK cells (Figure 4D). 


\section{PC Expression Confers Increased Migrating Capability on Canine Renal Tubular Cells}

Although defective cell-cell adhesion is one significant step to institute metastasis in malignancy, many other critical determinants are required to establish the malignant potential of the transformed cells. Increased cell migration is known to be one such determinant. ${ }^{19,20}$ To characterize the migrating potential of the PC knockdown cells, we used both transwell migration and wound healing assays. Although the mock transfected cells showed significant migration toward a chemotaxic gradient set up by hepatocyte growth factor, we found that the PC knock-down clones migrated less efficiently, with only $50 \%$ of the cells migrating through the Transwell plates (Figure 5A). In contrast, the migration potential was reverted in the $\mathrm{R}$ clones. Wound healing assays on confluent monolayers composed of $\mathrm{M}$, $\mathrm{Si}$, or $\mathrm{R}$ clones also demonstrated a significantly compromised migration of PC knock-down clones compared with the mock-control and $\mathrm{PC}$ re-expressing clones (Figure $5 \mathrm{~B}$ ). As Rac1 is well known to play a major role in cell motility and invasion/ migration, ${ }^{21,22}$ it is likely that PC affects cell migration through its effect on Rac1 activity.

\section{PC Interaction with EBP50 Is Required for Its Regulatory Effect on Rac1 Activation}

Podocalyxin is known to interact with the ERM family protein ezrin either directly or indirectly through the linkage of EBP50 (ERM-binding phosphoprotein 50), and PC overexpression has been demonstrated to activate the small GTP binding protein RhoA presumably through the trapping of the inhibitory protein RhoGDI by ezrin, which assumes an open conformation to expose its RhoGDI binding domain after interacting with PC. ${ }^{23}$ Recently, PC was demonstrated to increase the aggressiveness of breast and prostate cancer cell lines through its interaction with ezrin. ${ }^{24}$ As RhoGDI also negatively regulates another small GTPase Rac1, we hypothesize that PC overexpression leads to trapping of RhoGDI at the cell membrane and a subsequent relief of the inhibitory regulation of RhoGDI on Rac1. To test this hypothesis, we first constructed plasmids expressing either the aminoterminal half of ezrin (N-ezrin), which interacts with $\mathrm{RhoGDI}^{25}$ or the complementary carboxy-terminal ezrin (C-ezrin). Interestingly, $\mathrm{N}$-ezrin was resistant to triton $\mathrm{X}$-100 detergent, implying a tighter association with the actin cytoskeleton than the soluble C-ezrin (Figure 6A). When HEK293 cells were tranfected with N-ezrin expressing constructs, Rac1 was activated compared with the C-ezrin transfected cells (Figure 6A). The above finding demonstrates that the RhoGDI binding domain of ezrin could activate endogenous Rac1. Because PC is known to interact with the ERM family protein ezrin either directly or indirectly through the linkage of EBP50, we next explored whether the activation of Rac1 by PC depended on its interaction with ezrin and EBP50. To accomplish this goal, we transfected various PC constructs into HEK293 cells, which express endogenous ezrin and

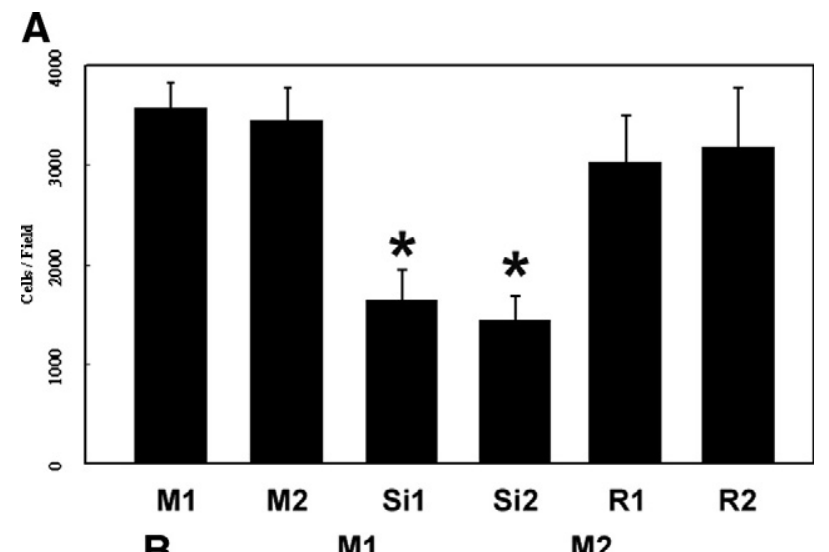

B

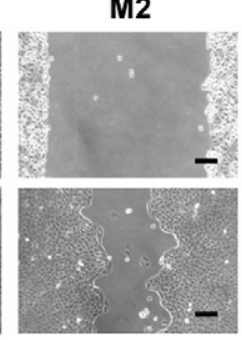

$\mathrm{Si2}$

oh
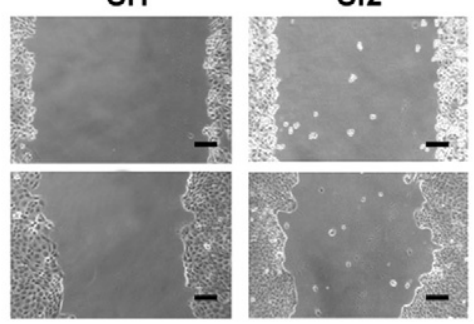

R1

R2

oh
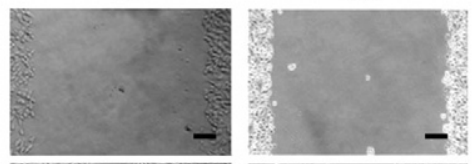

$16 \mathrm{~h}$
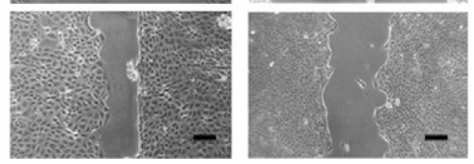

Figure 5. Podocalyxin (PC) knock-down results in diminished cell migration. A: Transwell migration assay was performed on M, Si, and R MDCK clones treated with $50 \mathrm{ng} / \mathrm{ml}$ recombinant human hepatocyte growth factor. After 15 hours, migrated cells were fixed, stained, and counted. The data shown were means \pm SE of each triplicate assay. ${ }^{*} P<0.05$ versus M 1 clone. B: Wound healing assay was used to assess the migrating behaviors of MDCK cells on loss of contact inhibition. Photographs were taken when wounds were generated $(0 \mathrm{~h})$ and 16 hours after wounding $(16 \mathrm{~h})$ at the selected sites. Magnification bars, $20 \mu \mathrm{m}$.

EBP50 but not any PC homologue. ${ }^{7,15}$ Only cells transfected with full-length PC, but not the deletion constructs devoid of the C-terminal PDZ binding motif ( $d C$ ) or most of the entire cytoplasmic domain ( $\mathrm{SC}$ ), could activate Rac1 in HEK293 (Figure 6B). Although an in vitro pulldown assay indicated that the $\mathrm{dC}$ mutant retained the binding capacity with ezrin (see Supplemental Figure S3 at $h$ ttp://ajp.amjpathol.org), it failed to activate Rac1 similar to the $\mathrm{SC}$ mutant that could bind neither ezrin nor EBP50. To examine whether the missing connection to EBP50, but not other PDZ domain containing proteins, is 
A
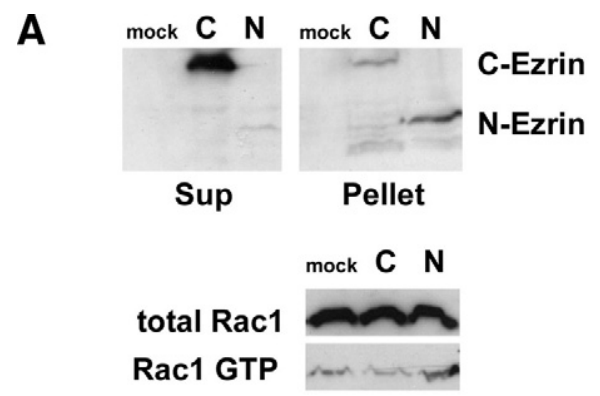

B

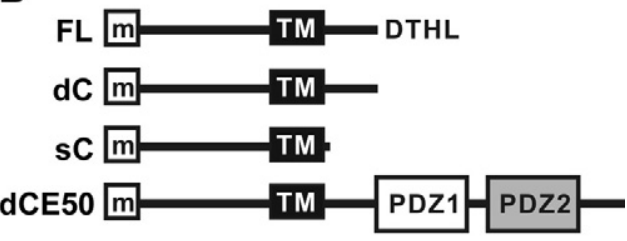

mock FL dC sC dCE50

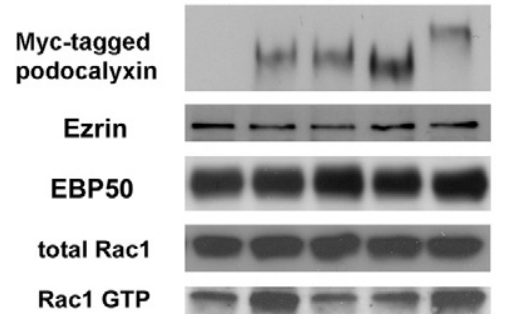

Figure 6. Podocalyxin/EBP50/ezrin complex activates Rac1. A: HEK293 cells were transfected with empty vector (mock), plasmid constructs expressing HA-tagged carboxy-terminal (C), or amino-terminal ezrin (N). One day after the transfection, the transfected cells were washed once in ice-cold Tris-buffered saline and scraped with ice-cold lysis buffer $(20 \mathrm{mmol} / \mathrm{L}$ Tris, $1 \%$ TX-100, $500 \mathrm{mmol} / \mathrm{L} \mathrm{NaCl}, 15 \%$ glycerol, $10 \mathrm{mmol} / \mathrm{L} \mathrm{MgCl}_{2}, 0.5 \mathrm{mmol} / \mathrm{L}$ DTT, $1 \mathrm{mmol} / \mathrm{L}$ PMSF). Lysates were clarified at $13,000 \mathrm{~g}$ for 10 minutes to examine the distribution of the expressed proteins between triton X-100 detergent soluble (Sup) and insoluble (Pellet) portions by Western blotting analysis using anti-HA antibody. Rac1 activation was assessed from the lysates using GST-PBD pull down assay. B: HEK293 cells were transfected with empty vector (mock), plasmid constructs expressing Myc-tagged full length podocalyxin (FL), podocalyxin devoid of the terminal PDZ domain binding motif sequence DTHL (dC), podocalyxin deleting most of the cytoplasmic sequence except the 5 juxta-membrane amino acids (sC), or dC mutant fused with full-length EBP50 (dCE50). Cell lysates were harvested one day after transfection and processed for Western blotting analysis of Myctagged PC, endogenous EBP50, and ezrin expression, and in parallel for Rac1 activation assays. In the diagram, $m$ indicates Myc epitope tag; TM, transmembrane domain; PDZ1 and PDZ2, the tandem PDZ domains of EBP50.

the reason for compromising Rac1 activating ability of $\mathrm{dC}$, we generated a construct expressing the $\mathrm{dC}$ mutant fused with full-length EBP50 (dCE50 in Figure 6B). This fusion protein restored full activation of Rac1 when transfected into HEK293 cells. The finding that $\mathrm{dC}$ and $\mathrm{sC}$ mutants both failed to activate Rac1 together with the restoration of Rac1 activation by dCE50 indicates that both EBP50 and ezrin are necessary to fully activate Rac1 by PC.

\section{Rac1 Activation by PC Overexpression Is Dependent on the Interaction between EBP50 and ARHGEF7}

It has been proposed that PC recruits RhoGDI through ezrin to release the inhibitory effect of RhoGDI on RhoA
A

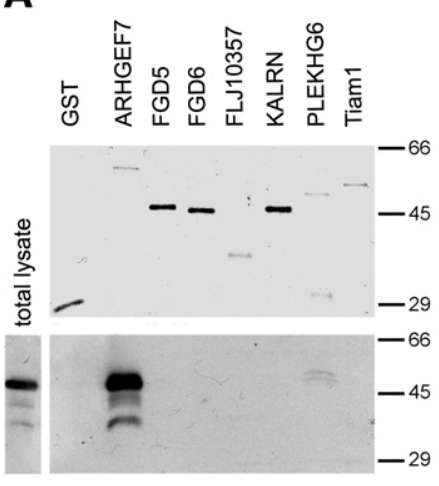

B

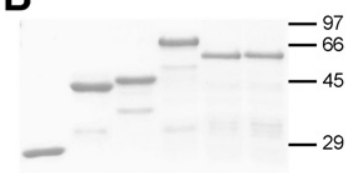

GST GST- GST- GST- GST- GSTE50. E50. E50. F7. F7.
Z1 Z2 FL DC

GST GST

GST-E50.FL GST PDZ1 PDZ2

GST-E50.Z1 GST PDZ1

GST-E50.Z2 GST PDZ2

GST-F7.C GST

GST-F7.DC GST

C
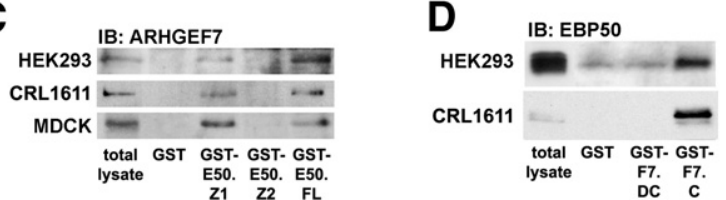

Figure 7. ARHGEF7 interacts with the first PDZ domain of EBP50 through it C-terminal PDZ domain binding motif. A: Rac1 GEF candidates with potential EBP50 interacting PDZ motif were cloned and expressed as GST fusion proteins and purified onto glutathione beads. Upper panel: coomassie blue stained gel showed the purity of seven candidate Rac1GEFs. Lower panel: MDCK lysates were incubated with glutathione beads that had been loaded with individual Rac1GEF, and after washing, the bounded materials were separated on SDS-PAGE and analyzed by Western blotting using EBP50 antibody. B: Coomassie blue-stained gel showed the purity of GST fused first PDZ domain of EBP50 (E50.Z1), second PDZ domain of EBP50 (E50.Z2), full-length EBP50 (E50.FL), C-terminal one third of ARHGEF7 deleted off its PDZ binding motif (F7.DC), and C-terminal one third of ARHGEF7 (F7.C). In the diagram, the first and second PDZ domain of EBP50 are labeled as white and gray boxes, respectively, whereas ARHGEF7 is represented as a slashed rectangle and the terminal PDZ-binding motif ETNL. C: In vitro GST fusion proteins pull down assays showed only the first PDZ domain of EBP50 (E50.Z1), and full-length EBP50 (E50.FL) could pull down ARHGEF7 from HEK293, renal carcinoma cell line CRL1611, and MDCK lysates. D: In vitro GST fusion proteins pull down assays showed only intact C-terminal domain of ARHGEF7 (F7.C), but not the PDZ binding motif defective mutant (F7.DC), could pull down EBP50 from HEK293, and CRL1611 lysates. The positions of the molecular weight markers in kilodaltons were shown on the right in $\mathbf{A}$ and $\mathbf{B}$.

GTPase activity. Our new finding of not only ezrin but also EBP50 being important in activating Rac1 implies that relieving the inhibitory function of RhoGDI is not sufficient. Given that complete activation of small GTPases requires both a GDI and a GEF (guanine nucleotide exchange factor), we suspected that EBP50 plays a role in recruiting a GEF to activate Rac1. We further hypothesize that this putative Rac1 GEF interacts with the first PDZ domain of EBP50 because the second PDZ domain of EBP50 binds PC. To validate our hypothesis, we performed extensive bioinformatics research and selected several candidates that fulfilled the conditions of both being a Rac1 GEF and possessing a PDZ motif that fit favorably into the binding pocket in the second PDZ domain of EBP50. These include: (1) PLEKHG6, which displays a GEF activity preferentially on RhoG and interacts with ezrin, (2) KALRN, which relays the message from Arf6 to Rac1 and could interact with PDZ domain containing proteins such as PSD-95 and SAP97, (3) FLJ10357, which is also known as Solo and interacts with RhoG and Rac1, (4) Tiam-1 (tumor invasion and metastasis 1), which activates Rac1 and contains a PDZ binding motif, (5) FGD5 and (6) FGD6, both of which contain FYVE and 


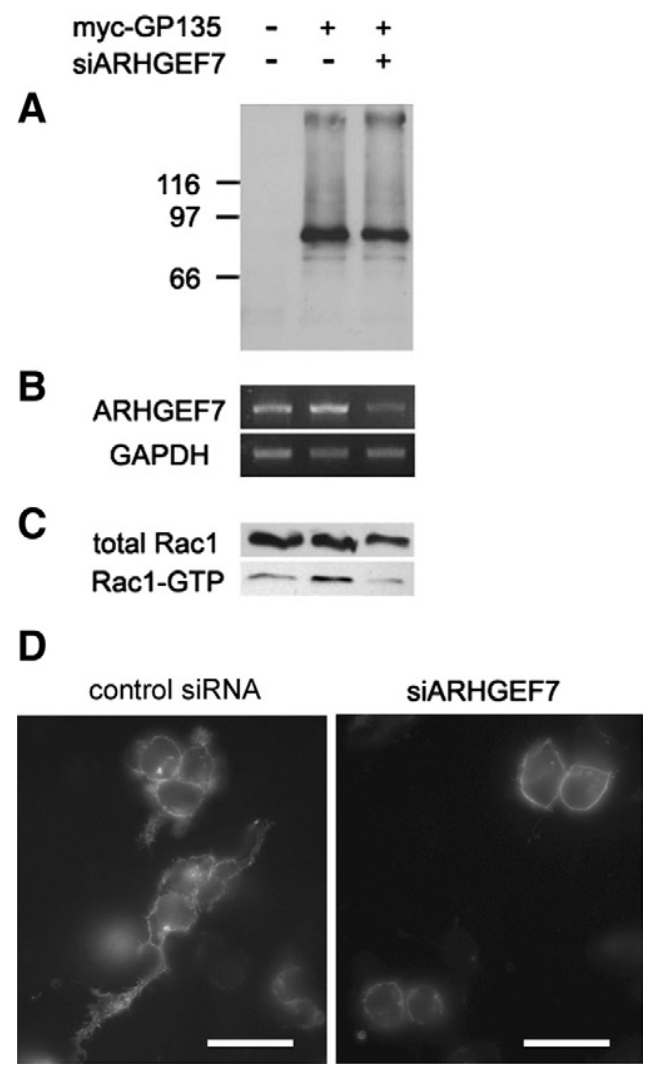

Figure 8. GP135/podocalyxin activates Rac1 GTPase activity through an ARHGEF7-dependent pathway. HEK293 cells, which express endogenous EBP50 and ARHGEF7, but not podocalyxin, were transfected with podocalyxin construct with or without siRNA targeted for ARHGEF7. The cells were evaluated with (A) Western blotting analysis for the expression of Myctagged Gp135 and (B) for the endogenous expression of ARHGEF7 by RT-PCR. C: Rac1 activity assay was performed as described in the legend of Figure 4C. D: HEK293 cells were transfected with $0.5 \mu \mathrm{g}$ Myc-tagged Gp135 expressing plasmid and 20 picomole of small interfering RNA duplex targeted at human ARHGEF7 (right) or the control RNA duplex (left) in $1 \mu \mathrm{l}$ Lipofectamine 2000 according to the instruction manual from Invitrogen. Cells were processed for immunofluorescence study 16 hours after transfection using mouse anti-Myc antibody (9E10). Magnification bar, $20 \mu \mathrm{m}$.

$\mathrm{PH}$ domain, and act as an RhoGEF, and (7) ARHGEF7, which is also known as $\beta$-Pix and COOL 1 . This GEF is unique in its capability of binding both Rho family GTPases and their downstream effectors such as PAK kinase through its $\mathrm{SH} 3$ domain.

To test which one(s) of these potential candidates could interact with EBP50, we cloned cDNA for each of the above mentioned genes and generated GST fusion constructs for in vitro pull-down experiments. The results showed only ARHGEF7 interacted strongly with EBP50 (Figure 7A). Therefore, we performed more in-depth experiments. Further binding assays using recombinant proteins (Figure 7B) made from deletion mutant constructs indicated that ARHGEF7 binds to EBP50 using its carboxyl terminal PDZ motif (Figure 7C), whereas EBP50 indeed interacts with ARHGEF7 through its first PDZ domain (Figure 7D).

Furthermore, although Rac1 activity, assessed by GSTPAK fusion protein pull-down assay, increased on exogenous podocalyxin over-expression, the expression of siRNA against ARHGEF7 inhibited this increment of Rac1 activity (Figure 8, A-C). While PC-transfected HEK293 cells tended

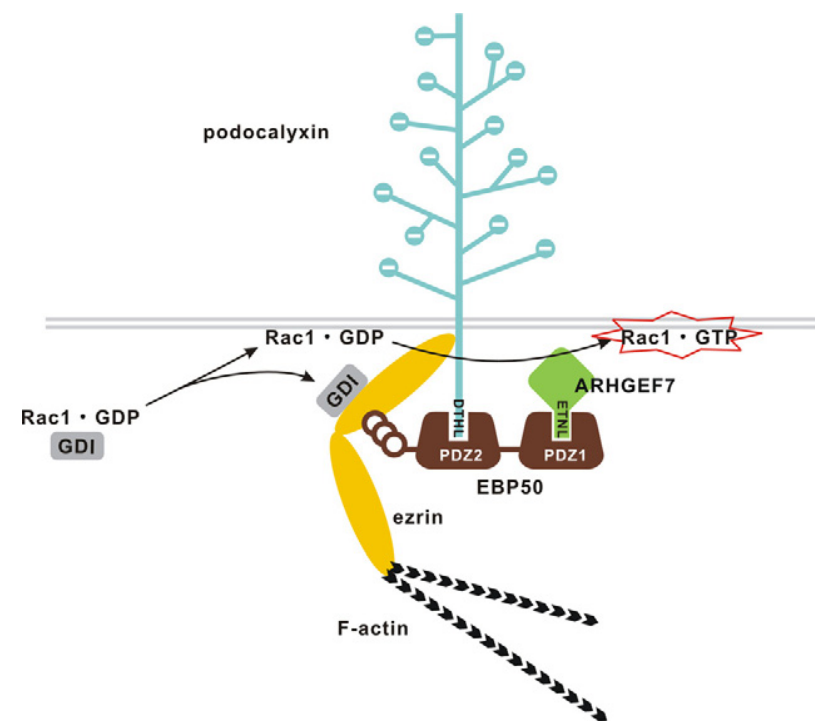

Figure 9. The transmembrane podocalyxin at the apical domain binds to the second PDZ domain of EBP50 (PDZ2, brown-colored) through its PDZbinding motif DTHL, whereas the membrane cytoskeleton adaptor protein ezrin (yellow-colored) binds simultaneously to EBP50 and the membraneproximal region of podocalyxin. The amino-terminal domain of ezrin traps RhoGDI and thereby relieves the small GTPase Rac1 from the negative regulator RhoGDI. We propose that besides negating the inhibitory effect of RhoGDI though ezrin, EBP50 plays an additional role in recruiting a guanine nucleotide exchange factor (ARHGEF7, green colored) to fulfill the activation cycle of Rac1. This interaction is through the C-terminal PDZ binding motif (ETNL) of ARHGEF7 and the first PDZ domain of EBP50 (PDZ1). In this schematic model Rac1 is depicted, but RhoA small GTPase could be regulated in an analogous way.

to be more spread out and possessed long and branched membrane protrusions, ARHGEF7-inhibited cells appeared to have much less membrane protrusion (Figure 8D). This indicates the increased Rac1 activity associated with overexpressed PC (Figures 4C and 6B) is mediated through an ARHGEF7 dependent pathway.

\section{Discussion}

Our study identified the anti-adhesive molecule PC as a metastasis-promoting factor in a subset of human RCC subjects, which constituted $9.6 \%$ of our entire RCC patient group. This result echoes surprisingly well the result reported earlier for breast cancer, ${ }^{9}$ wherein the percentage of that study population expressing high levels of PC was $6 \%$. This similarity indicates that PC could be one of the factors involved in the complicated network controlling tumor cell biology and that only a discrete section of cancer patients suffer from the perturbation of PC expression. Our study indicates that the prognostic value of PC status in predicting distant metastasis as well as diseasespecific and overall survivals is independent of histological subtype and clinical staging (Table 2). RCC patients with stage III tumors face a wide spectrum of prognosis. The locally advanced nature of tumors at this stage often bewilders surgeons as to whether aggressive treatment should be supplemented after tumor excision. To address this clinically important issue, we performed an analysis in our stage III patients according to their PC expression status. Multivariate Cox regression analysis 
showed that the hazard ratio of PC overexpression was $4.22(95 \% \mathrm{Cl}=1.42-12.5, P=0.009)$ for metastasis-free survival and $8.21(95 \% \mathrm{Cl}=2.28-29.49, P=0.001)$ for disease-specific survival. Our result emphasizes PC overexpression as the most significant single risk factor for tumor metastasis and survival in stage III RCC patients among other traditional risk factors including age and sex as well as tumor size, grade, and histological type. This finding would facilitate the identification of a subset of patients categorized as early clinical disease status who, however, carry an increased risk of metastasis for more aggressive treatment modalities to improve long-term prognosis.

Metastasis takes place after cells accumulate a series of cellular aberrations, and our finding of Rac1 activation by overexpressing PC (Figures 4 and 6) implies that PC expression plays an important dual regulatory role in determining both cell adhesion (Figure 3) and cell migration (Figure 5), which are fundamental in the metastatic capability of malignant cells.

Cell migration is a highly integrated process that orchestrates embryonic morphogenesis, tissue repair, and regeneration. It also plays a pivotal role in the metastasis of cancer. Tumor cell invasion into the surrounding tissue contributes a large part to the significant morbidity and mortality of cancer patients. The initial response of a cell to a migration-promoting agent is to polarize and extend protrusions, which consists of large broad lamellipodia or spike-like filopodia, in the direction of the attractant. In either case, these protrusions are driven by actin polymerization and can be stabilized by extracellular matrix adhesion or cell-cell interactions. Rac1 small GTP-binding protein has been previously characterized in the directional migration process, which involves a reciprocal activation of PI3 kinase pathway. ${ }^{26,27}$ The frontal end of migrating cells shares some interesting analogy to the apical domain of polarized epithelial cells. PC is localized at the apical surface of podocytes, and canine PC (Gp135) is the canonical apical domain marker in the wellestablished MDCK-polarized epithelial model. Our finding of an instrumental role of PC in Rac1 activation provides a mechanistic insight into the way the migrating cells could restrict the localized Rac1 activation and initiate the reciprocal PI3 kinase activation pathway at the chosen migrating front to maintain the moving momentum.

By transfecting various PC mutant constructs into HEK293, which expresses endogenous ezrin and EBP50 but not PC, we demonstrated the Rac1 activation capability of PC depends on its interaction with both ezrin and EBP50 (Figure 6B). Recently, PC was reported to enhance malignant potential of breast and prostate epithelial cells through an ezrin-dependent pathway. ${ }^{24}$ Our finding further implies simple recruiting of ezrin by PC at the membrane is required but not sufficient to activate the cell migration signals without the participation of EBP50, a protein containing two PDZ domains. PDZ domains are protein interaction domains that mediate the assembly of multiprotein complexes and facilitate signaling transduction at particular sites inside cells. Although previous study suggested PC activates RhoA by trapping the inhibitory RhoGDI protein through ezrin, ${ }^{23}$ complete acti- vation of Rho family small GTPases such as RhoA and Rac1 requires both suppression of RhoGDI and the recruitment of GEFs. Bioinformatics analysis reveals that $40 \%$ of human Rho-GEFs contain a putative PDZ-binding motif at the $\mathrm{C}$ terminus. ${ }^{28}$ It is conceivable that the role of EBP50 could be recruiting a putative Rac1 GEF through its PDZ domain so as to facilitate the GDP/GTP exchange of Rac1 after RhoGDI has been trapped and inhibited by ezrin. Indeed, our findings demonstrate EBP50 serves to link RhoGDI indirectly through ezrin and ARHGEF7, a Rac1 GEF, via its second PDZ domain. Binding of EBP50 to $\mathrm{PC}$ through its second PDZ domain then anchors EBP50 to plasma membrane so that it could play an important dual regulatory role in removing the inhibitory role of RhoGDI and recruiting upstream GEF such as ARHGEF7 to complete the activation loop of Rac1 at cell membranes (Figure 9). The function of EBP50 in malignancy progression has been controversial, with reports showing EBP50 associated with either tumor-suppressing or -enhancing function. ${ }^{29-32}$ Whether this discrepancy could be attributable to the PC expression status in the cancer specimen is certainly an intriguing issue and worthy of further investigation.

\section{References}

1. Doyonnas R, Kershaw DB, Duhme C, Merkens H, Chelliah S, Graf T, McNagny KM: Anuria, omphalocele, and perinatal lethality in mice lacking the CD34-related protein podocalyxin. J Exp Med 2001, 194:13-27

2. Takeda T, Go WY, Orlando RA, Farquhar MG: Expression of podocalyxin inhibits cell-cell adhesion and modifies junctional properties in Madin-Darby canine kidney cells. Mol Biol Cell 2000, 11:3219-3232

3. Palmer RE, Kotsianti A, Cadman B, Boyd T, Gerald W, Haber DA: WT1 regulates the expression of the major glomerular podocyte membrane protein Podocalyxin. Curr Biol 2001, 11:1805-1809

4. Stanhope-Baker P, Kessler PM, Li W, Agarwal ML, Williams BR: The Wilms tumor suppressor-1 target gene podocalyxin is transcriptionally repressed by p53. J Biol Chem 2004, 279:33575-33585

5. Herrera L, Ottolenghi C, Garcia-Ortiz JE, Pellegrini M, Manini F, Ko MS, Nagaraja R, Forabosco A, Schlessinger D: Mouse ovary developmental RNA and protein markers from gene expression profiling. Dev Biol 2005, 279:271-290

6. Vitureira N, McNagny K, Soriano E, Burgaya F: Pattern of expression of the podocalyxin gene in the mouse brain during development. Gene Expr Patterns 2005, 5:349-354

7. Lin WL, Pang VF, Liu CH, Chen JY, Shen KF, Lin YY, Yu CY, Hsu YH Jou TS: Pleomorphic extra-renal manifestation of the glomerular podocyte marker podocalyxin in tissues of normal beagle dogs. Histochem Cell Biol 2007, 127:399-414

8. Doyonnas R, Nielsen JS, Chelliah S, Drew E, Hara T, Miyajima A, McNagny KM: Podocalyxin is a CD34-related marker of murine hematopoietic stem cells and embryonic erythroid cells. Blood 2005, 105:4170-4178

9. Somasiri A, Nielsen JS, Makretsov N, McCoy ML, Prentice L, Gilks CB, Chia SK, Gelmon KA, Kershaw DB, Huntsman DG, McNagny KM, Roskelley CD: Overexpression of the anti-adhesin podocalyxin is an independent predictor of breast cancer progression. Cancer Res 2004, 64:5068-5073

10. Casey G, Neville PJ, Liu X, Plummer SJ, Cicek MS, Krumroy LM, Curran AP, McGreevy MR, Catalona WJ, Klein EA, Witte JS: Podocalyxin variants and risk of prostate cancer and tumor aggressiveness. Hum Mol Genet 2006, 15:735-741

11. Riccioni R, Calzolari A, Biffoni M, Senese M, Riti V, Petrucci E, Pasquini L, Cedrone M, Lo-Coco F, Diverio D, Foa R, Peschle C, Testa $U$ : Podocalyxin is expressed in normal and leukemic monocytes. Blood Cells Mol Dis 2006, 37:218-225 
12. Kelley TW, Huntsman D, McNagny KM, Roskelley CD, Hsi ED: Podocalyxin: a marker of blasts in acute leukemia. Am J Clin Pathol 2005, 124:134-142

13. Yasuoka H, Tsujimoto M, Hirokawa M, Tori M, Nakahara M, Miyauchi A, Kodama R, Sanke T, Nakamura Y: Podocalyxin expression in undifferentiated thyroid carcinomas. J Clin Pathol 2008, 61:1228-1229

14. Heukamp LC, Fischer HP, Schirmacher P, Chen X, Breuhahn K, Nicolay C, Buttner R, Gutgemann I: Podocalyxin-like protein 1 expression in primary hepatic tumours and tumour-like lesions. Histopathology 2006, 49:242-247

15. Cheng HY, Lin YY, Yu CY, Chen JY, Shen KF, Lin WL, Liao HK, Chen YJ, Liu CH, Pang VF, Jou TS: Molecular identification of canine podocalyxin-like protein 1 as a renal tubulogenic regulator. J Am Soc Nephrol 2005, 16:1612-1622

16. Criss AK, Ahlgren DM, Jou TS, McCormick BA, Casanova JE: The GTPase Rac1 selectively regulates Salmonella invasion at the apical plasma membrane of polarized epithelial cells. J Cell Sci 2001, 114:1331-1341

17. Takeichi M: Functional correlation between cell adhesive properties and some cell surface proteins. J Cell Biol 1977, 75:464-474

18. Jou TS, Nelson WJ: Effects of regulated expression of mutant RhoA and Rac1 small GTPases on the development of epithelial (MDCK) cell polarity. J Cell Biol 1998, 142:85-100

19. Gupta GP, Massague J: Cancer metastasis: building a framework. Cell 2006, 127:679-695

20. Steeg PS: Tumor metastasis: mechanistic insights and clinical challenges. Nat Med 2006, 12:895-904

21. Michiels F, Habets GG, Stam JC, van der Kammen RA, Collard JG: A role for Rac in Tiam1-induced membrane ruffling and invasion. Nature 1995, 375:338-340

22. Keely PJ, Westwick JK, Whitehead IP, Der CJ, Parise LV: Cdc42 and Rac1 induce integrin-mediated cell motility and invasiveness through PI(3)K. Nature 1997, 390:632-636

23. Schmieder S, Nagai M, Orlando RA, Takeda T, Farquhar MG: Podocalyxin activates $\mathrm{RhoA}$ and induces actin reorganization through
NHERF1 and Ezrin in MDCK cells. J Am Soc Nephrol 2004, 15:2289-2298

24. Sizemore S, Cicek M, Sizemore N, Ng KP, Casey G: Podocalyxin increases the aggressive phenotype of breast and prostate cancer cells in vitro through its interaction with ezrin. Cancer Res 2007, 67:6183-6191

25. Takahashi K, Sasaki T, Mammoto A, Takaishi K, Kameyama T, Tsukita S, Takai Y: Direct interaction of the Rho GDP dissociation inhibitor with ezrin/radixin/moesin initiates the activation of the Rho small G protein. J Biol Chem 1997, 272:23371-23375

26. Wang F, Herzmark P, Weiner OD, Srinivasan S, Servant G, Bourne HR: Lipid products of $\mathrm{PI}(3) \mathrm{Ks}$ maintain persistent cell polarity and directed motility in neutrophils. Nat Cell Biol 2002, 4:513-518

27. Weiner OD, Neilsen PO, Prestwich GD, Kirschner MW, Cantley LC, Bourne HR: A PtdlnsP(3)- and Rho GTPase-mediated positive feedback loop regulates neutrophil polarity. Nat Cell Biol 2002, 4:509-513

28. Garcia-Mata R, Burridge K: Catching a GEF by its tail. Trends Cell Biol 2007, 17:36-43

29. Shibata T, Chuma M, Kokubu A, Sakamoto M, Hirohashi S: EBP50, a beta-catenin-associating protein, enhances Wnt signaling and is over-expressed in hepatocellular carcinoma. Hepatology 2003, 38: $178-186$

30. Pan Y, Wang L, Dai JL: Suppression of breast cancer cell growth by $\mathrm{Na}+/ \mathrm{H}+$ exchanger regulatory factor 1 (NHERF1). Breast Cancer Res 2006, 8:R63

31. Kreimann EL, Morales FC, de Orbeta-Cruz J, Takahashi Y, Adams H, Liu TJ, McCrea PD, Georgescu MM: Cortical stabilization of betacatenin contributes to NHERF1/EBP50 tumor suppressor function. Oncogene 2007, 26:5290-5299

32. Song J, Bai J, Yang W, Gabrielson EW, Chan DW, Zhang Z: Expression and clinicopathological significance of oestrogen-responsive ezrin-radixin-moesin-binding phosphoprotein 50 in breast cancer. Histopathology 2007, 51:40-53 